\title{
Axial uniformity of diamond-like carbon film deposited on metal rod by using microwave-sheath voltage combination plasma
}

\author{
Xingrui Deng, Yasuyuki Takaoka, Hiroyuki Kousaka, and NoritsuguUmehara, \\ Department of Mechanical Science and Engineering, Graduate School of Engineering \\ Nagoya University, Furo-cho, Chikusa-ku, Nagoya 464-8603, Japan \\ E-mail address: deng@ume.mech.nagoya-u.ac.jp \\ E-mail address: takaoka@ume.mech.nagoya-u.ac.jp \\ E-mail address: kousaka@mech.nagoya-u.ac.jp \\ E-mail address: ume@mech.nagoya-u.ac.jp
}

(C) 2013. This manuscript version is made available under the Elsevier user license http://www.elsevier.com/open-access/userlicense/1.0/ 


\section{Abstract}

We developed a novel method for the deposition of diamond-like carbon (DLC) films at high deposition rates (over $100 \mu \mathrm{m} / \mathrm{h}$ ) using microwave-sheath voltage combination plasma. This method was applied for depositing a DLC film on a three-dimensional metal substrate, but we found that the film thickness was not uniform along the direction of microwave propagation. Hence, we investigated the factors affecting the axial uniformity of DLC film deposited on long metal rods (1 $\mathrm{cm}$ in diameter). Since the axial distribution of plasma was observed to affect the uniformity of DLC, we evaluated the axial distribution of ion density using a Langmuir Probe in Ar plasma that was generated along both DLC-coated and non-coated rods. The results showed that the ion density along the axis of the DLC-coated rod decayed at a shorter distance than that along the axis of the uncoated one. The voltage of the ion sheath presumably decreased owing to the voltage drop in the DLC film with high resistivity, in accordance with the short microwave decay. The uniformity considerably improved by using a duty ratio of $50 \%$ for the pulsed operation of both the microwaves and the substrate bias at $-200 \mathrm{~V}$. When the substrate voltage was increased to $-500 \mathrm{~V}$, the hardness of the DLC film measured by the nano-indenter was about $25 \mathrm{GPa}$, uniformly distributed along the rod axis. Raman results show that the film is typical DLC structure, and the structure shows 
good uniformity along the rod axis.

\section{Key words}

Microwave-sheath voltage combination plasma, Diamond-like carbon, Langmuir probe,

Uniformity 


\section{Introduction}

Diamond-like carbon (DLC) films are widely used as protective coatings and have many applications because of their excellent mechanical properties such as high hardness, low friction, and high wear resistance [1]. However, in conventional DLC-film preparation techniques, the deposition rate is too low, which constrains the mass production of these films. Previous works have investigated the deposition rate by various methods and all have reported low values. For example, R. D. Mansano et al. reported a deposition rate of $2.16 \mu \mathrm{m} / \mathrm{h}$ by magnetron sputtering [2], F. Garrelie et al. reported 3.6 $\mu \mathrm{m} / \mathrm{h}$ by laser deposition [3], and Ronghua Wei reported $5 \mu \mathrm{m} / \mathrm{h}$ by plasma-based ion implantation and deposition [4]. The relatively low deposition rate of DLC films in these techniques could be attributed to the low plasma density (electron density $N_{\mathrm{e}}<$ $10^{10} \mathrm{~cm}^{-3}$ ) near the substrate. However, H. Kousaka et al. developed a new technique that enables generation of higher density plasma $\left(N_{\mathrm{e}}>10^{11} \mathrm{~cm}^{-3}\right)$ adjacent to the metal substrate [5]. In their work, 2.45-GHz surface waves were guided along a negatively biased conductive rod to generate high-density Ar plasma $\left(N_{\mathrm{e}}>10^{11} \mathrm{~cm}^{-3}\right)$ along the rod shape. The plasma therein obtained is called microwave-excited high-density near plasma because it is generated as if the plasma has been stuck to the adjacent metal surface [5-7]. 
As shown in Fig.1(c), the aforementioned plasma is sustained by microwave surface waves [8] along the plasma-sheath-metal interface [5-7]. Without the sheath expansion, microwaves exhibit a short decay distance and as such, plasma does not spread along metal surfaces. For practical applications, it is essential to expand the sheath width by increasing the sheath voltage using an external DC power supply $[6,7]$. In other words, an external power supply and the injection of microwaves are both essential to take advantage of the microwave-excited, high-density near plasma for use in coating applications. This method of plasma generation is called the Microwave-sheath Voltage-combination Plasma (MVP) method. Note that similar high-density plasma generated adjacent to a metal surface cannot be obtained by any other method that gives glow-type discharge. For example, Capacitively coupled plasma (CCP) using RF bias results in much less electron density than MVP (Fig. 1a), and a remote-type high-density plasma such as conventional surface wave-excited plasmas (SWP) significantly decays from the generation region to the substrate (Fig.1b). Therefore, the MVP method is a novel technique to obtain high-density plasma $\left(\mathrm{N}_{\mathrm{e}}>10^{11} \mathrm{~cm}^{-3}\right)$ that can be sustained along an adjacent metal surface.

A high deposition rate can be achieved by using the MVP method in plasma-enhanced chemical vapor deposition (PECVD), because plasma density near the 
substrate is much higher in the MVP method than in other conventional methods (Fig. 1). Thus, we propose a new type of PECVD apparatus employing the MVP method for ultra-high-speed coating of DLC (Fig. 2).

Surface waves propagate along the surface of a three-dimensional metal substrate such that the entire surface of the substrate can be completely coated by MVP [9]. However, the axial thickness of the film is non-uniformly distributed, whereas the thickness of DLC typically decreases to half of the original thickness, or less, in 1-cm increments along the direction of microwave propagation [10]. For the newly proposed apparatus to have usable applications, the issue of non-uniformity was considered as the most important problem to be improved. Thus, in this work, we investigated the mechanism of the non-uniform appearance by using long metal long rods as substrates, and we thus found an effective method to improve the uniformity.

\section{Experimental setup}

A schematic of the microwave-excited PECVD apparatus with a stainless-steel chamber (225 $\mathrm{mm}$ in inner diameter and $220 \mathrm{~mm}$ in height) for DLC coating is shown (Fig. 2(a)). The chamber is evacuated by using of a mechanical booster pump and a rotary pump, and the base pressure of the chamber is $1.1 \mathrm{~Pa}$. Microwaves $(2.45 \mathrm{GHz})$ are introduced via a coaxial waveguide (WX-39D) and injected into the chamber 
through a quartz plate. A steel rod substrate $(\Phi 10 \mathrm{~mm} \times 150 \mathrm{~mm})$ is inserted into the center of the quartz plate. Here, the center of the bottom end of the rod substrate is defined as the origin in a cylindrical coordinate configuration, or $(z, r)=(0,0)$. The substrate is connected to a high-voltage DC power supply with tungsten wire $(0.5 \mathrm{~mm}$ in diameter) in order to apply a negative voltage against the grounded chamber.

The experimental parameters for the DLC coating are summarized in Table 1. In order to sustain plasma during processing, a pulsed negative voltage of $V_{\text {sub }}=-200 \mathrm{~V}$ was applied to the rod at a pulse frequency $f_{\text {pulse }}(\mathrm{Hz})$ and duty ratio $D_{\mathrm{v}} \%$, thus synchronizing a pulsed injection of $2.45-\mathrm{GHz}$ microwaves with a peak power of $P_{\mathrm{m}}=$ $1000 \mathrm{~W}$ at the same pulse frequency and duty ratio. Microwaves introduced into the chamber will propagate as surface waves along the interface between the plasma column and the ion sheath surrounding the rod. The rod substrate was cleaned for 10 min by Ar ion sputtering. The rod surface was then treated for $15 \mathrm{~min}$ by plasma nitriding in order to improve the adhesion between the specimen surface and DLC film. Lastly, DLC film was deposited in a gas mixture composed of $\mathrm{CH}_{4} / \mathrm{Ar} / \mathrm{TMS}$ and left to be mixed for $40 \mathrm{~s}$. In deposition process, the pulse current was monitored, as shown in Fig.2 (b).

The thickness at different position was measured by surface profiler (Mitutoyo 
SV-3100). The mask on the rod was made by conductive adhesive before deposition.

The structure of the film was evaluated by Raman spectrum (Jasco NRS-1000, $532 \mathrm{~nm}$ laser). The Raman scattering was excited in the wave-number range of $600-2200 \mathrm{~cm}^{-1}$. The hardness of coatings was measured by nano-scale indentation (Elionix ENT-1100) employing a diamond Berkovich indenter. The indentation load was determined to be $500 \mu \mathrm{N}$.

\section{Results and discussion}

Figures 3 (a) and (b) show the plasma column at the beginning and at the end of the deposition process. At the beginning of the deposition, the rod is totally covered by a bright plasma column, and by the end of the deposition process, the plasma column no longer covers the top third of the rod. This result indicates that the plasma column shrinks to the bottom of the rod during the deposition process. Note that the substrate current during deposition rapidly decreased with increasing the coating time, as shown in Fig.3 (c).

The thickness distribution of the DLC film coated along the axial direction is shown in Fig. 4, in which the inset is a photograph of the DLC-coated rod substrate. An interference fringe appears along the axis of the DLC-coated substrate, indicating the 
axially distributed coating thickness. The values of measured thickness show axial non-uniformity in the DLC film: the thickness changes from $4.6 \mu \mathrm{m}$ measured at the bottom of the rod to an immeasurable value at the top of the rod. The deposition rate at the bottom end was $414 \mu \mathrm{m} / \mathrm{h}$, which shows the promising potential of the MVP method for ultra-high-speed $(>100 \mu \mathrm{m} / \mathrm{h})$ coating of DLC. However, as mentioned earlier, for practical use of this new method, the issue of non-uniformity must be addressed. The non-uniform distribution of film thickness can be attributed to the distribution of plasma density along the rod substrate during the deposition. We considered that the non-uniformity in the plasma thickness could be enhanced by the plasma shrinkage that occurs with increased coating time (Fig. 3). In order to clarify the reason for the plasma shrinkage, the axial distribution of ion density in Ar plasma generated along the DLC-coated and uncoated rods were evaluated using a Langmuir probe to determine whether the DLC film itself affects the occurrence of plasma shrinkage.

Fig. 5 shows the configuration of the chamber for the Langmuir probe measurement. The ion density distributions along both the DLC-coated and non-coated rods were measured in order to investigate the effect of the DLC film on the plasma distribution. The Langmuir probe is inserted in the axial direction $(r=3 \mathrm{~cm})$ and is equipped with an automatic linear drive to measure the axial variation of plasma properties [11]. Ar was 
employed as the working gas, at a flow rate of flow $14 \mathrm{sccm}$, and the pressure was maintained at $40 \mathrm{~Pa}$. To generate plasma, 2.45-GHz microwaves were injected continuously into the chamber, at an input power of $200 \mathrm{~W}$. A continuous DC voltage of $-200 \mathrm{~V}$ was applied to the rod during the microwave injection. The ion density values were recorded in $1-\mathrm{cm}$ increments, from $z=2 \mathrm{~cm}$ to $z=15 \mathrm{~cm}$.

Figures. 6(a) and 6(b) show the measured distributions of Ar ion density along the DLC coated and uncoated rods, respectively. The results show that when the DC bias is $0 \mathrm{~V}$, the ion density distributions under the different rod conditions (DLC-coated and uncoated) are very similar. These results indicate that the DLC film has little effect on microwave propagation, as surface waves, when no bias is supplied to the rod. For the uncoated rod (Fig. 6(a)), the ion density distribution becomes more uniform with increasing bias voltage. The previously confirmed effect of substrate bias to homogenize the distribution of plasma along the metal rod [5-7,11], was thus confirmed in this work as well. In other words, as explained in Ref. [11], the increasing substrate bias steadily increased the sheath voltage that accompanied the expansion of sheath width between the plasma and the substrate, which ultimately resulted in the plasma extension and homogenization along the rod axis. Conversely, for the DLC-coated rod (Fig. 6(b)), the ion density distribution was almost unchanged from -50 to $-200 \mathrm{~V}$, indicating that the 
DLC film suppressed the effect of substrate bias in order to homogenize the plasma distribution in MVP. Thus, it can be concluded that the DLC film itself induced the non-uniform distribution of plasma during DLC coating using the MVP method, (Figs. 3 and 4).

The reason for the plasma shrinkage with increasing coating time during the DLC deposition is explained in Ref [7], specifically that the voltage supplied to the ion sheath in the MVP method homogenizes the plasma distribution along the metal rod. Since the distribution of plasma was not changed by an increase in the substrate voltage from -50 to $-200 \mathrm{~V}$, we can conclude that the substrate voltage did not increase the sheath voltage. We assume that this phenomenon was caused by the relatively high resistivity [12] of our DLC film itself, and it accompanied the decrease in pulse current with coating time, as shown in Fig. 3(c). In other words, it is possible that the voltage drop in the film from the pulse current, $V_{\text {DLC, }}$ reduced $V_{\text {sheath-owing to the high-resistivity of the DLC coating }}$ (Fig. 7). Consequently, it is possible that the effect of substrate bias on homogenizing the plasma distribution along the DLC-coated rod was suppressed with coating time.

Based on the above-mentioned interpretation, the high resistivity of the DLC film likely caused the observed plasma shrinkage (Figs. 3(b) and 4). Hence, by decreasing the resistivity of the DLC film, we could reasonably expect to achieve a more uniform 
distribution of film thickness. Therefore, to control the resistivity of the DLC, we varied the duty ratio of the substrate bias $\left(D_{\mathrm{v}}\right)$. The DLC coatings were conducted at three different duty ratios of substrate bias $(\mathrm{DC}=25,35$, and $50 \%)$, whereas the duty ratio of the microwaves was kept at $\mathrm{MW}=50 \%$. Note that all of the coating parameters except $D_{\mathrm{v}}$ were kept the same as those listed in Table 1 . The waveforms of the pulsed substrate bias and the microwaves employed were turned on at the same time, in one pulse. In the cases of $\mathrm{DC}=25 \%$ and $35 \%$, the substrate bias is turned off before the microwave is stopped, in one pulse, whereas in the case of $\mathrm{DC}=50 \%$, both the substrate bias and the microwave are turned off at the same time.

The pulse current was monitored during the DLC coating and was found to change with increasing deposition time (Fig. 9). In the case of $\mathrm{DC}=25 \%$, the substrate current decreased rapidly, whereas in the case of $\mathrm{DC}=35 \%$, the substrate current was slightly larger during the first $15 \mathrm{~s}$ and decreased rapidly thereafter. The substrate current in the case of $\mathrm{DC}=50 \%$ was above $0.5 \mathrm{~A}$ throughout the entire process. These results indicate that the substrate current increased with the increase in the duty ratio of the substrate bias. Further, rapid decay in the substrate current was not observed when the duty ratio of the substrate bias was $50 \%$.

The plasma shrinkage that occurred for $\mathrm{DC}=25 \%$ did not occur for $\mathrm{DC}=50 \%$. In 
DLC deposition, the film is softened or becomes polymer-like without substrate bias [13], and hence, the result in Fig. 9 can be interpreted as follows (Fig. 10). For DC = $25 \%$, an induced polymer-like DLC with high resistivity deposits on the substrate during the latter part of one pulse where microwave plasma is generated without substrate bias, and this process results in significantly increased resistivity of the DLC film (Fig. 10a). The increase in the DLC film resistance with coating time and the subsequently observed plasma shrinkage from the decrease in sheath voltage could be caused by the increase in voltage drop in the DLC film (Fig. 7). For DC $=35 \%$, the amount of polymer-like DLC in one pulse is decreased, resulting in the slightly decreased resistivity of DLC film, but the resistivity was still relatively high and thus caused a similarly rapid decrease in pulse current. For DC $=50 \%$, the induced polymer-like DLC was not deposited in one pulse, which resulted in the significantly decreased resistivity of the DLC film, and this film did not cause a rapid decrease in pulse current because the sheath voltage was not decreased in this DLC film (Fig.10b). The axial distributions of DLC film deposited at the three different duty ratios of substrate bias are shown in Fig 11. The uniformity of the film thickness was improved with the increase in the duty ratio of the substrate bias. A large sheath voltage, close to the substrate voltage, was kept relatively unchanged at $\mathrm{DC}=50 \%$, and subsequently, a 
uniform distribution of plasma column was observed at $t=0$ and remained essentially unchanged during the entire deposition.

Since it was found that the plasma shrinkage does not occur by setting the same duty ratio for the substrate bias and microwave, further improvement to the deposition uniformity at higher bias voltage is expected. To investigate this possibility, the DLC coating was conducted at a substrate bias of $-500 \mathrm{~V}$, with a duty ratio of $50 \%$ for both the substrate bias and microwave. The axial distribution of thickness and hardness of the DLC film deposited at $-500 \mathrm{~V}$ is shown in Fig. 12. The result shows that the uniformity of the DLC film was further improved compared to the previous result at $-200 \mathrm{~V}$ for DC $=50 \%$. This improvement was a result of the further homogenization of plasma owing to increased substrate bias $[6,7,11]$. The mechanical properties of the film were measured by a nano-indenter at a maximum indentation load of $0.5 \mathrm{mN}$. The hardness values varied in the range of 24-27 GPa and were distributed uniformly along the axis. Thus, the DLC film deposited at $-500 \mathrm{~V}$ with a duty ratio of $50 \%$ for both the substrate bias and microwave has sufficiently high hardness and excellent uniformity. Since the distribution of hardness is uniform under this condition, the plasma distribution along the axis of a DLC-coated rod is expected to improve only slightly. It has been suggested that injecting microwaves into both ends of the rod, as is done in duo-plasmaline (see 
Ref. [8]), could further homogenize the plasma distribution.

Raman spectra of DLC films at different positions along the rod axis were measured in order to evaluate the structure distribution, as shown in Fig. 13. The results show that the shape of the Raman spectra does not change a lot. The G-peak position is shifted to a low wave-number from 1,527 to $1,467 \mathrm{~cm}^{-1}$, this implies that the DLC film on the top of the rod shows more $\mathrm{sp}^{3}$ bond than bottom.[1] This is because that the graphitization due to the higher temperature occurs in the DLC film at the bottom.

\section{Conclusion}

This work demonstrated that a DLC film can be successfully deposited at a high deposition rate (greater than $100 \mu \mathrm{m} / \mathrm{h}$ ) using the Microwave-sheath Voltage combination Plasma (MVP) method. However, Langmuir Probe measurements of ion density distribution in Ar plasma generated along DLC-coated and uncoated metal rods showed that the plasma distribution along the rod becomes non-uniform from effects produced by the DLC film itself. Our results imply that the plasma shrinks toward the microwave injection point when the resistance of the DLC film is high enough to decrease the sheath voltage, owing to the voltage drop in the film. A DLC film deposited along a stainless-steel rod at duty ratios of $25 \%$ and $50 \%$ for the substrate bias and the microwaves, respectively, was considerably non-uniform. The uniformity of 
film thickness was improved by increasing the duty ratio of substrate bias, which served to suppress a rapid decrease in substrate current with coating time. The uniformity of film thickness was further improved by increasing the bias voltage from -200 to $-500 \mathrm{~V}$ at a duty ratio of $50 \%$ for both the substrate bias and the microwaves. Based on these results, the MVP method shows good potential for the preparation of DLC films with good quality and uniformity that can be deposited at considerably high rates for industrial applications.

\section{Acknowledgements}

This work was supported partly by Tokai Region Nanotechnology Manufacturing Cluster, Knowledge Cluster Initiative (The Second Stage), by a "Grant for Advanced Industrial Technology Development (No. 11B06004d)" in 2011 from the New Energy and Industrial Technology Development Organization (NEDO) of Japan, and by Adaptable and Seamless Technology Transfer Program through target-driven R\&D (High-Risk Challenge type), JST of Japan. 


\section{References}

[1] J. Robertson, Diamond-like amorphous carbon, Mater. Sci. Eng. R. 37 (2002) 129-281.

[2] F. Garrelie, A.S. Loir, C. Donnet, F. Rogemond, R. Le Harzic, M. Belin, E. Audouard, P. Laporte, Study of plasma expansion induced by femtosecond pulsed laser ablation and deposition of diamond-like carbon films. Surf. Coat. Tech. 163-164 (2003) 306-312

[3] R.D. Mansano, M. Massi, L.S. Zambom, P. Verdonck, P.M. Nogueira, H.S. Maciel, C. Otani, Effects of the methane content on the characteristics of diamond-like carbon films produced by sputtering. Thin Solid Films 373 (2000) 243-246

[4] R. Wei, C. Rincon, T.L. Booker, J.H. Arps, Magnetic field enhanced plasma (MFEP) deposition of inner surfaces of tubes. Surf. Coat. Tech. 188-189 (2004) 691-696

[5] H. Kousaka, N. Umehara, K. Ono, J. Xu, Microwave-excited high-density plasma column sustained along metal rod at negative voltage. Jpn. J. Appl. Phys. 44 (2005) $1154-1157$.

[6] H. Kousaka and N. Umehara, Study on the axial uniformity of surface wave-excited 
plasma column sustained along a metal rod. Transactions of the Materials Research Society of Japan 31 (2006) 487-490.

[7] H. Kousaka, J. Xu, and N. Umehara, Pressure dependence of surface wave-excited plasma column sustained along metal rod antenna. Vacuum 80 (2006) 1154-1160.

[8] Yu M. Aliev, H. Schluter, A. Shivarova, Guided-wave-produced plasmas. Berlin: Springer; 2000.

[9] T. Okamoto, H. Kousaka, N. Umehara, Proc. 3rd Int. Symp. on Advanced Plasma Science and its application for nitrides and nanomaterials (ISPLASMA2011), 178.

[10]Y. Takaoka, H. Kousaka, N. Umehara, Proc. $4^{\text {th }}$ Int. Symp. on Advanced Plasma Science and its application for nitrides and nanomaterials (ISPLASMA2012), 188.

[11]H. Kousaka, N. Umehara, Extension of surface-wave-excited high-density plasma column sustained along graphite rod target. Vacuum 80 (2006) 806-809.

[12]B. Paosawatyanyong, A. Muakngam and S. Thitianan. Electrical characteristics of DLC deposited by RF inductively coupled plasma process. Adv. Mater. Res. 93-94 (2010) 699-702

[13]E. Braca, J.M. Kenny, D. Korzec, J. Engemann. Transition from polymer-like to 
diamond-like carbon coatings synthesized by a hybrid radiofrequency-microwave plasma source. Thin Solid Films 394 (2001) 30-39 


\section{Figure Captions}

Fig. 1 Schematic illustration of plasma generation methods: (a) CCP: Capacitatively Coupled Plasma, (b) SWP: Surface Wave-excited Plasma (High-density remote plasma), (c) MVP: Microwave-sheath Voltage combination Plasma (High-density near plasma sustained along an adjacent metal substrate). All substrates are inside a grounded metal chamber.

Fig. 2 (a)Schematic of DLC coating equipment for a three-dimensional metal substrate employing high-density near plasma, which is sustained by microwaves propagating along plasma-sheath interface surrounding the adjacent surface of a metal substrate. (b) The pulse current through the substrate monitored in deposition process

Fig.3 Photographs of microwave-excited plasma column sustained along the rod substrate at (a) the beginning of DLC deposition, (b) the end of DLC deposition and (c) the current varied with deposition time.

Fig.4 Thickness of DLC film along the rod axis. The inset picture is the DLC-coated rod.

Fig.5 Schematic drawing of the chamber setup for Langmuir probe measurement of the Ar plasma column generated along the uncoated and DLC-coated rods (stainless-steel, SUS304, JIS). 
Fig. 6 The ion density distributions in Ar plasma column generated along (a) uncoated and (b) DLC-coated stainless-steel rods, obtained for different substrate voltages of 0 , $-50,-100,-150$, and $-200 \mathrm{~V}$.

Fig. 7 Schematic illustration of voltage distribution in the radial direction between substrate and chamber wall

Fig. 8 Illustration of the wave forms for the substrate bias and microwave, which are operated in a pulsed manner. The left, center, and right cases are named as 25\%(DC)-50\%(MW), 35\%(DC)-50\%(MW), and 50\%(DC)-50\%(MW), respectively, where $25 \%(\mathrm{DC})-50 \%(\mathrm{MW})$ means the duty ratios of 25 and $50 \%$ for substrate bias and microwave, respectively.

Fig.9 Time evolution of substrate current in one pulse during diamond-like carbon deposition, obtained for the 3 cases: $25 \%(\mathrm{DC})-50 \%(\mathrm{MW}), 35 \%(\mathrm{DC})-50 \%(\mathrm{MW})$, and $50 \%(\mathrm{DC})-50 \%(\mathrm{MW})$.

Fig. 10 (a) DLC deposition in one pulse and (b) effect of High resistivity DLC on plasma distribution. (DLC resistivity: $\mathrm{R}_{1}>\mathrm{R}_{2}>\mathrm{R}_{3}$, sheath thickness: $\mathrm{t}_{1}<\mathrm{t}_{2}<\mathrm{t}_{3}=\mathrm{t}_{0}$ )

Fig.11 Axial distributions of film thickness for the diamond-like carbon films coated at different 3 duty ratios of 25,30 and $50 \%$ for substrate bias and a fixed duty ratio of $50 \%$ for microwave. 
Fig. 12 Axial distributions of the film thickness and hardness for the diamond-like carbon film coated at the substrate bias of $-500 \mathrm{~V}$. Note that the same duty ratio of $50 \%$ was employed for both the substrate bias and microwave in pulsed plasma generation.

Fig. 13 Raman spectra of DLC films measured at different positions on rod substrate 


\section{Tables}

Table 1 Parameters for DLC deposition

\begin{tabular}{|c|c|c|c|c|c|c|c|c|c|}
\hline $\begin{array}{c}\text { Experiment } \\
\text { processes }\end{array}$ & $\begin{array}{c}\text { Gas/Flow } \\
\text { rate } \\
(\operatorname{sccm})\end{array}$ & $\begin{array}{l}\text { Pressure } \\
\text { (Pa) }\end{array}$ & $\begin{array}{c}\text { Peak } \\
\text { Power, } \\
P_{\mathrm{m}}(\mathbf{W}) \\
\end{array}$ & $\begin{array}{c}\text { Microwave } \\
\text { Pulse } \\
\text { Frequency } \\
f_{\text {pulse }}(\mathbf{H z}) \\
\end{array}$ & $\begin{array}{l}\text { Duty } \\
\text { ratio, } \\
D_{\mathrm{v}}(\%) \\
\end{array}$ & $\begin{array}{c}\text { Peak } \\
\text { voltage } \\
V_{\text {sub }}(\mathbf{V}) \\
\end{array}$ & $\begin{array}{c}\text { Substrate bias } \\
\text { Pulse } \\
\text { Frequency }\end{array}$ & $\begin{array}{l}\text { Duty } \\
\text { ratio, } \\
D_{\mathrm{v}}(\%) \\
\end{array}$ & Time \\
\hline Cleaning & $\begin{array}{l}\mathrm{Ar} / 7 \\
\mathrm{H}_{2} / 2\end{array}$ & 50 & & & 8 & & & 4 & $10 \mathrm{~min}$ \\
\hline Nitride & $\begin{array}{c}\mathrm{Ar} / 7.5 \\
\mathrm{H}_{2} / 3 \\
\mathrm{~N}_{2} / 7\end{array}$ & 50 & 1000 & 500 & 30 & -200 & $\begin{array}{c}\text { same as } \\
\text { microwave }\end{array}$ & 20 & $15 \mathrm{~min}$ \\
\hline Deposition & $\begin{array}{c}\mathrm{CH}_{4} / 200 \\
\mathrm{Ar} / 40 \\
\mathrm{TMS} / 20\end{array}$ & 75 & & & 50 & & & 25 & $40 \mathrm{~s}$ \\
\hline
\end{tabular}




\section{Figures}

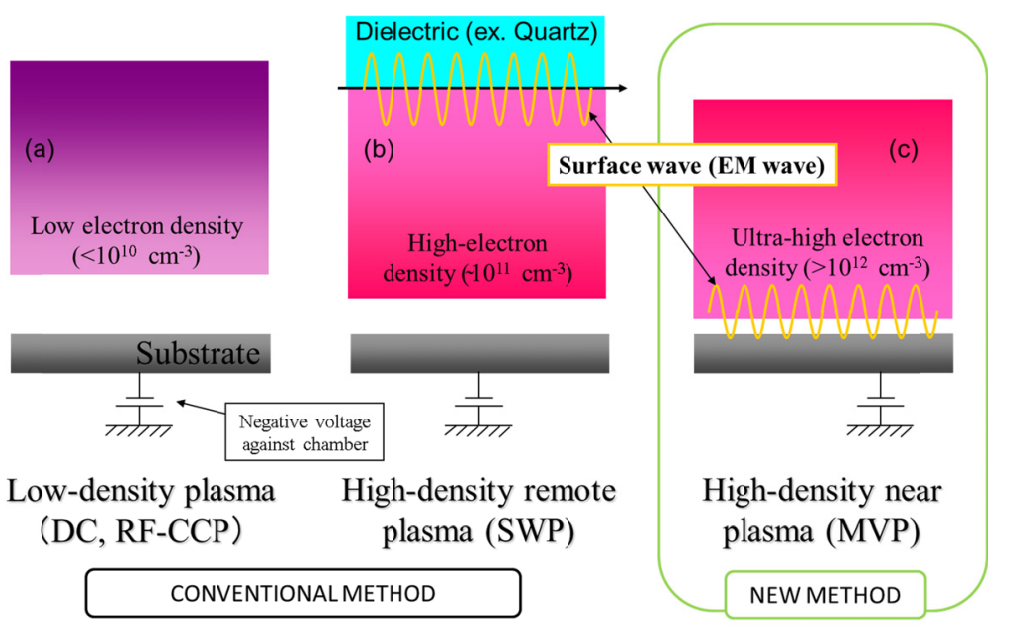

Fig. 1

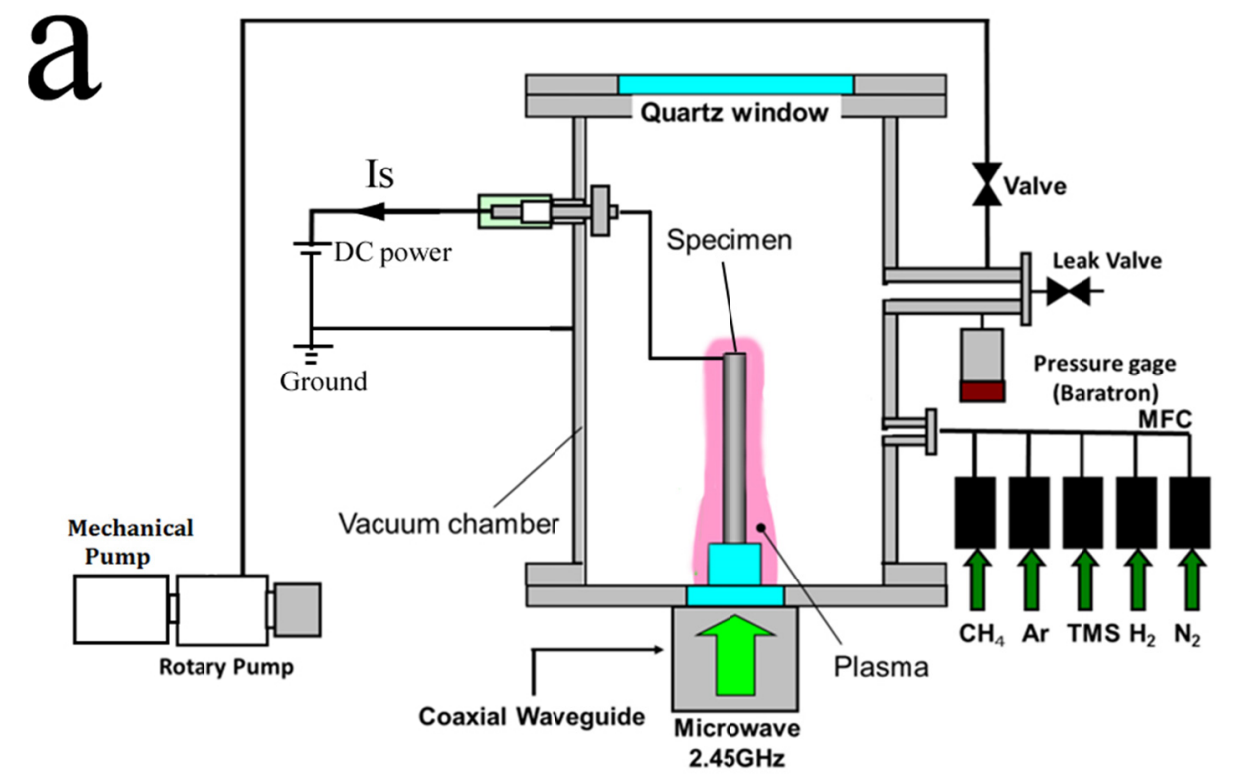




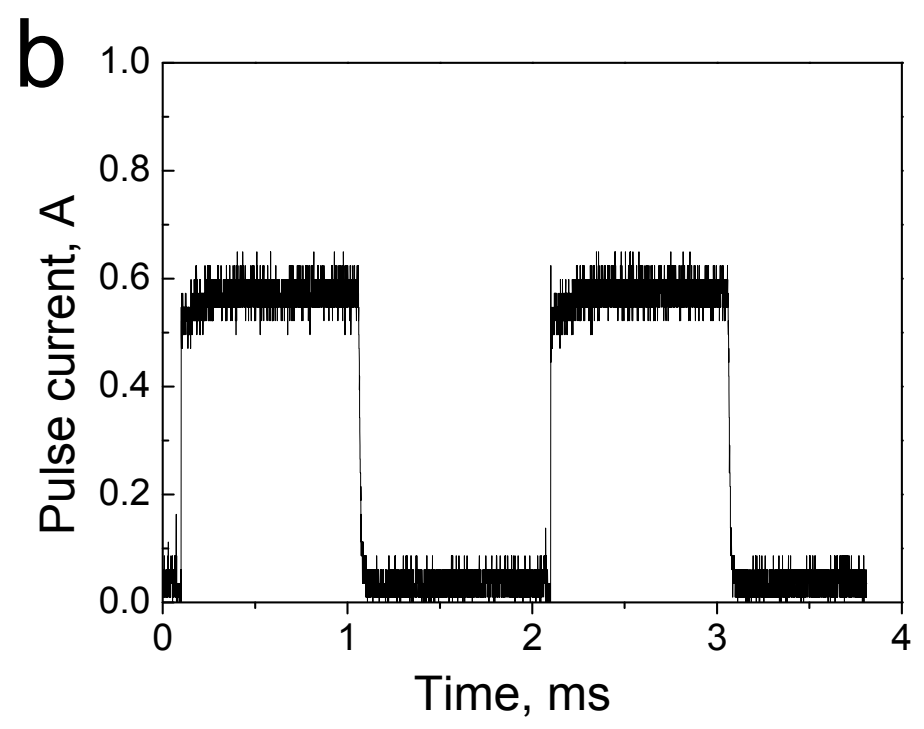

Fig. 2 

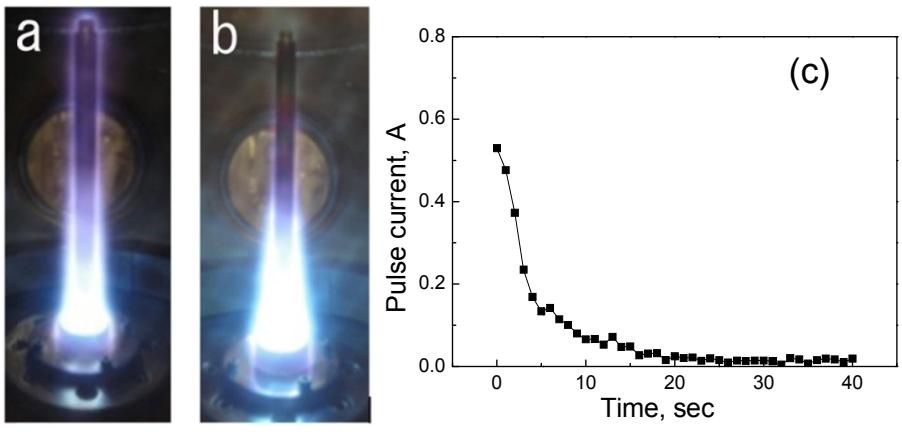

Fig. 3

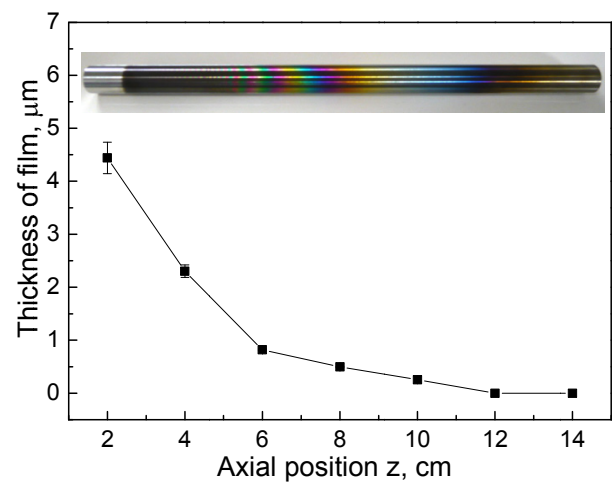

Fig. 4

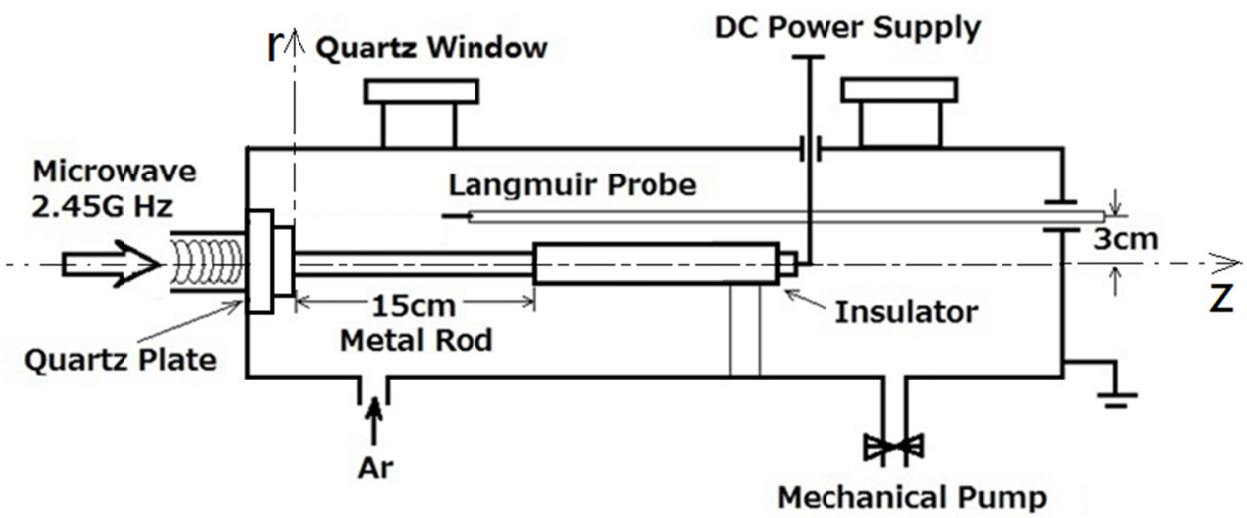

Fig. 5 

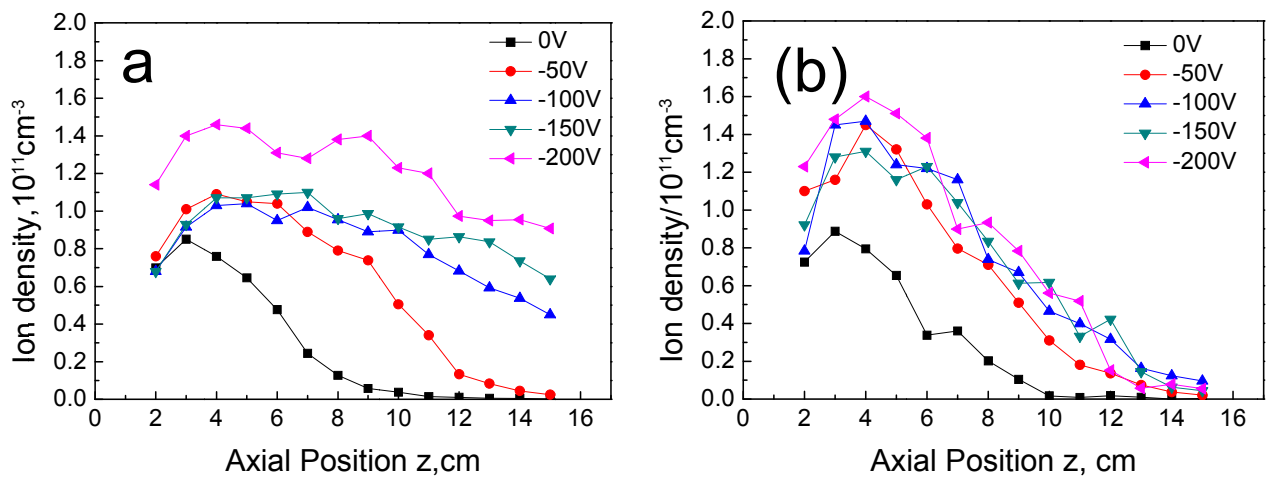

Fig. 6

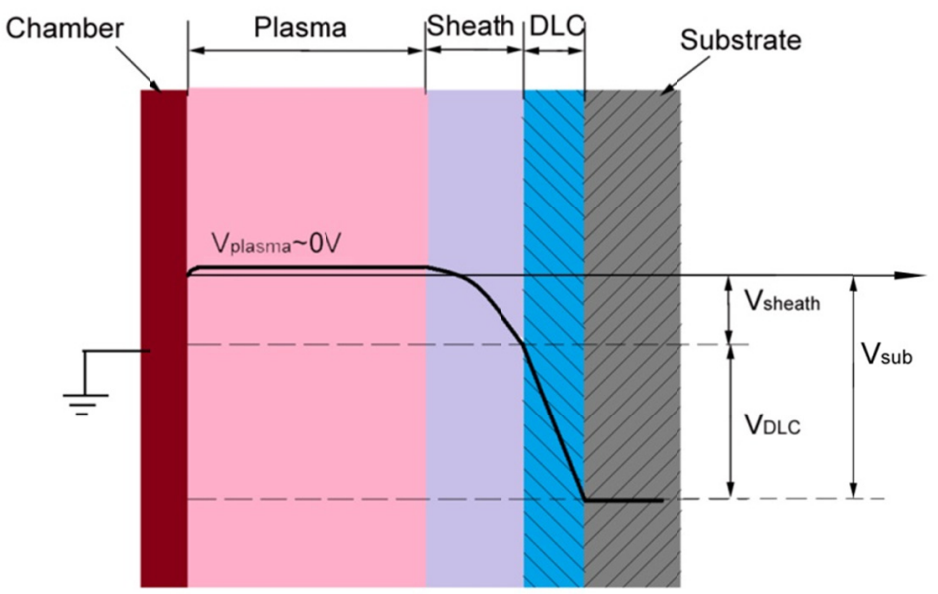

Fig. 7

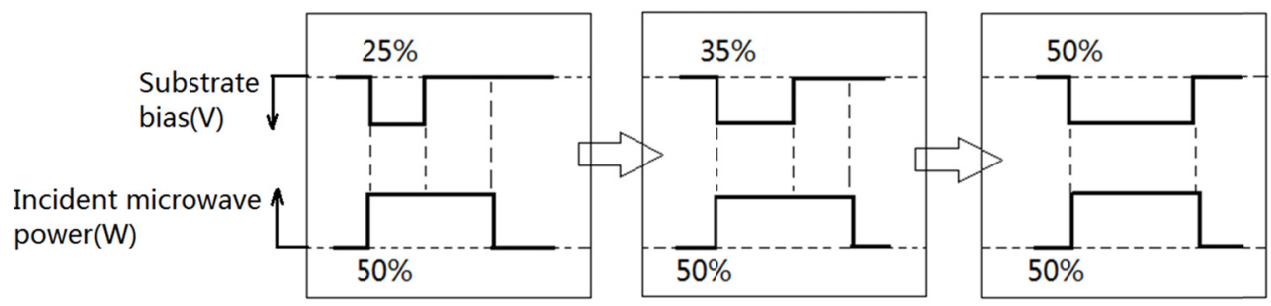

Fig. 8 


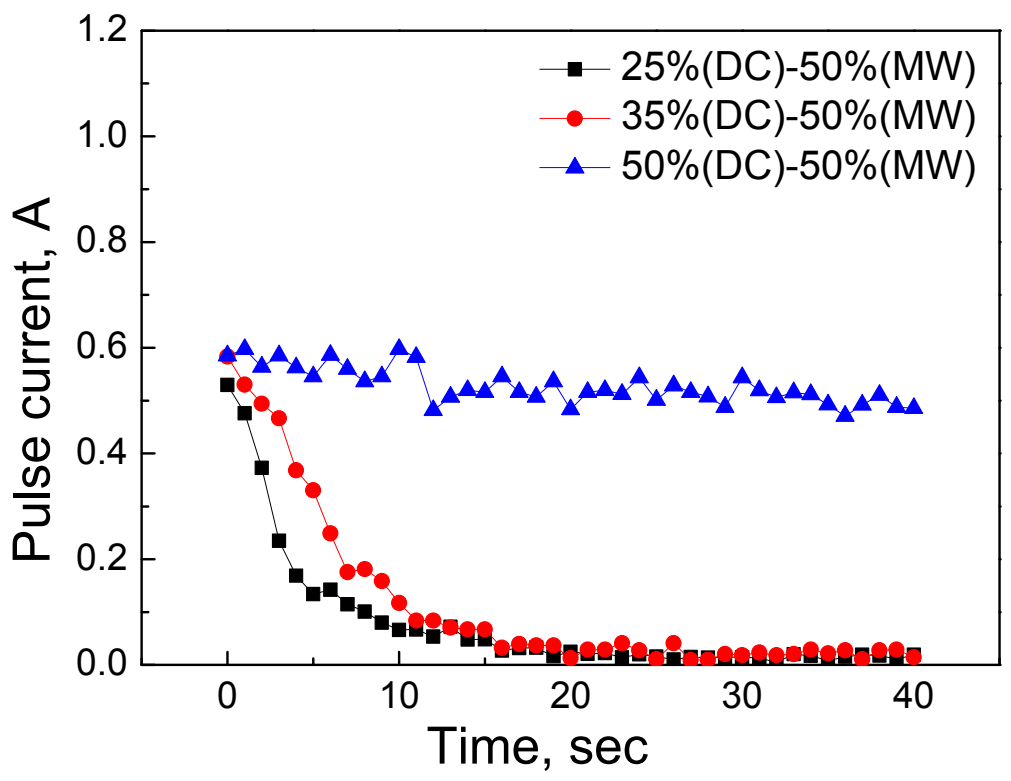

Fig. 9 
(a)

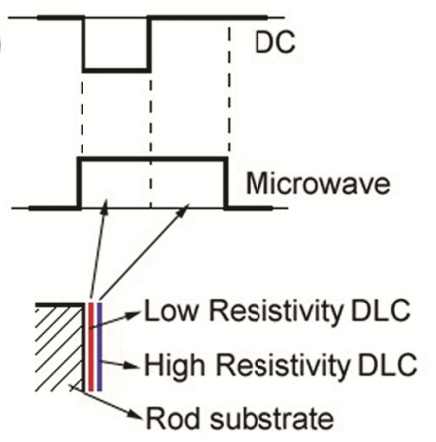

(b)
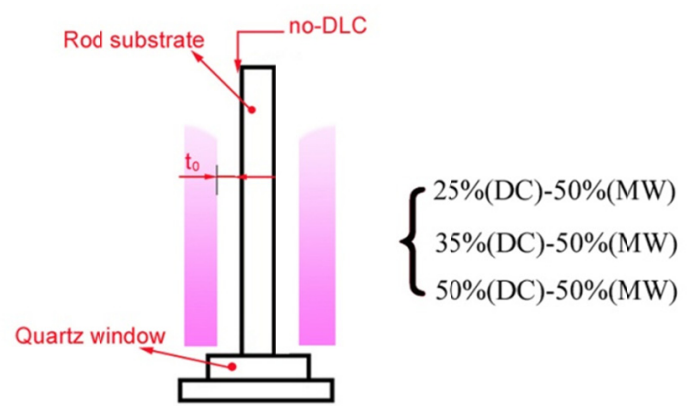

$\mathrm{t}=0 \mathrm{~s}$
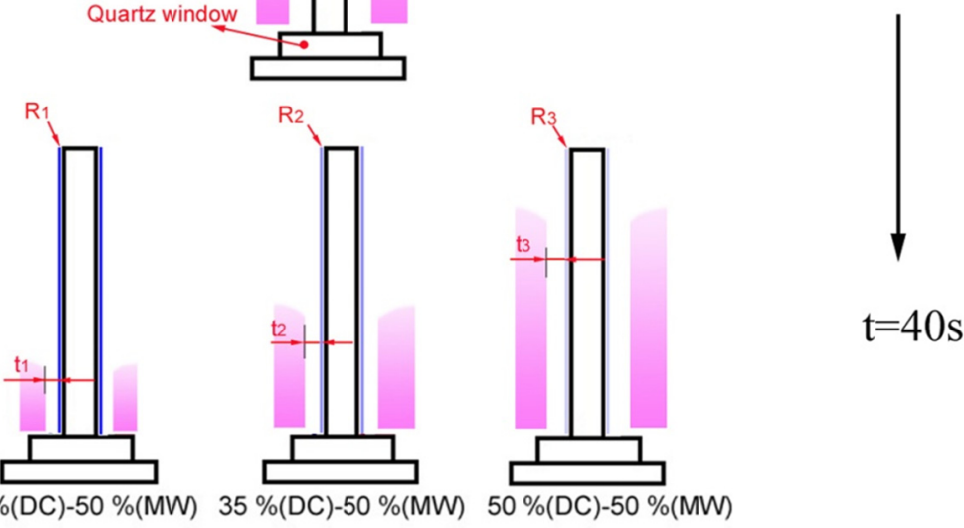

Fig. 10 


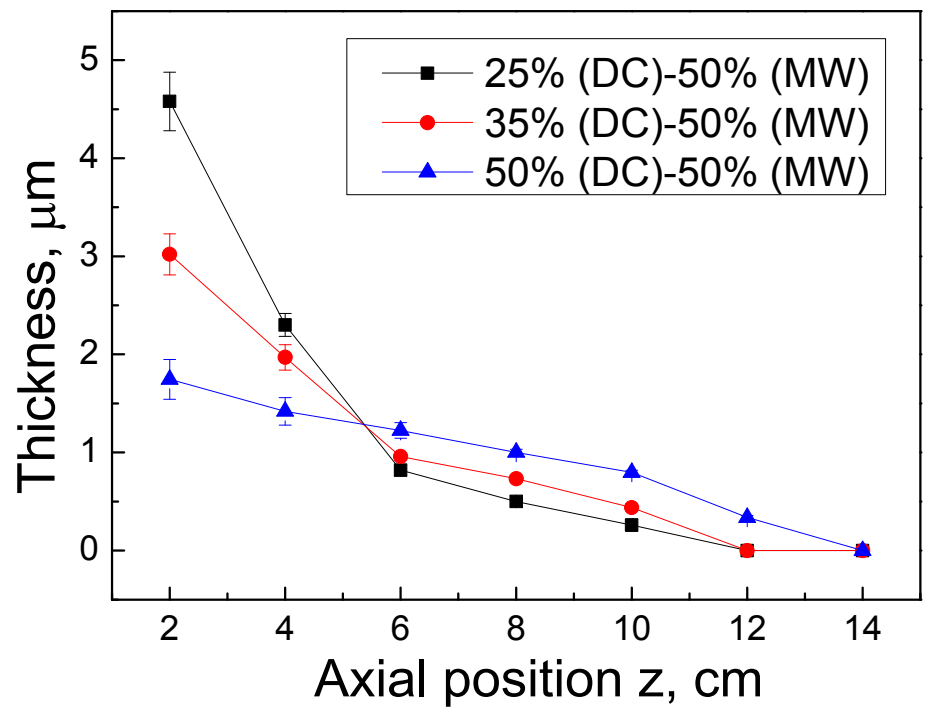

Fig. 11

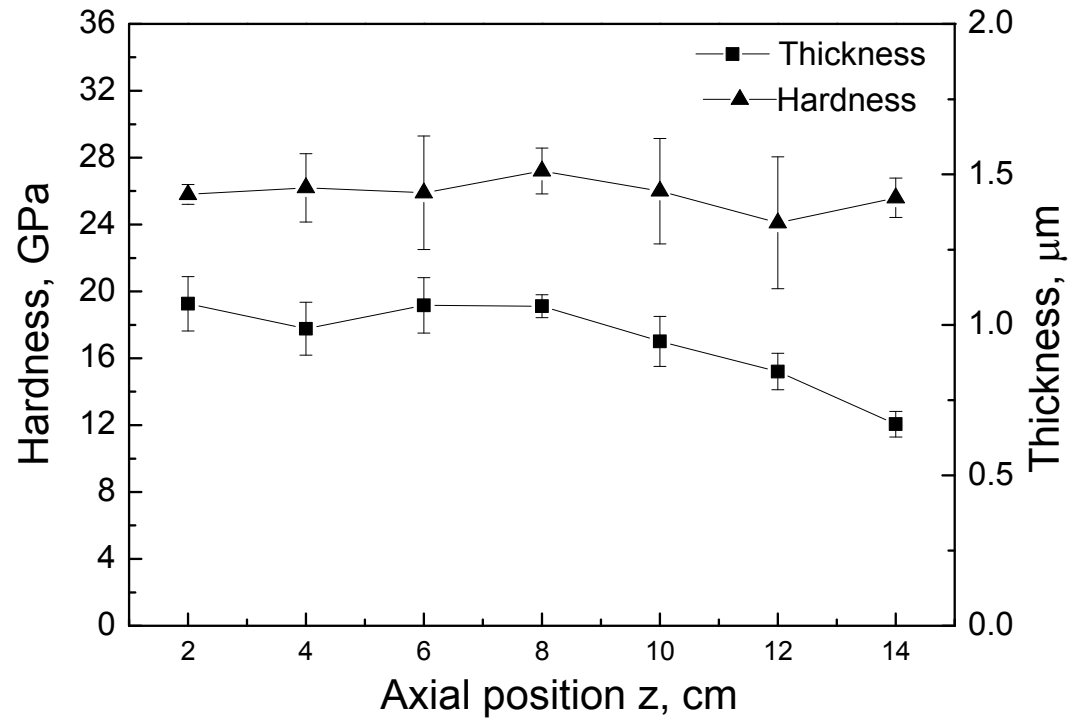

Fig. 12 


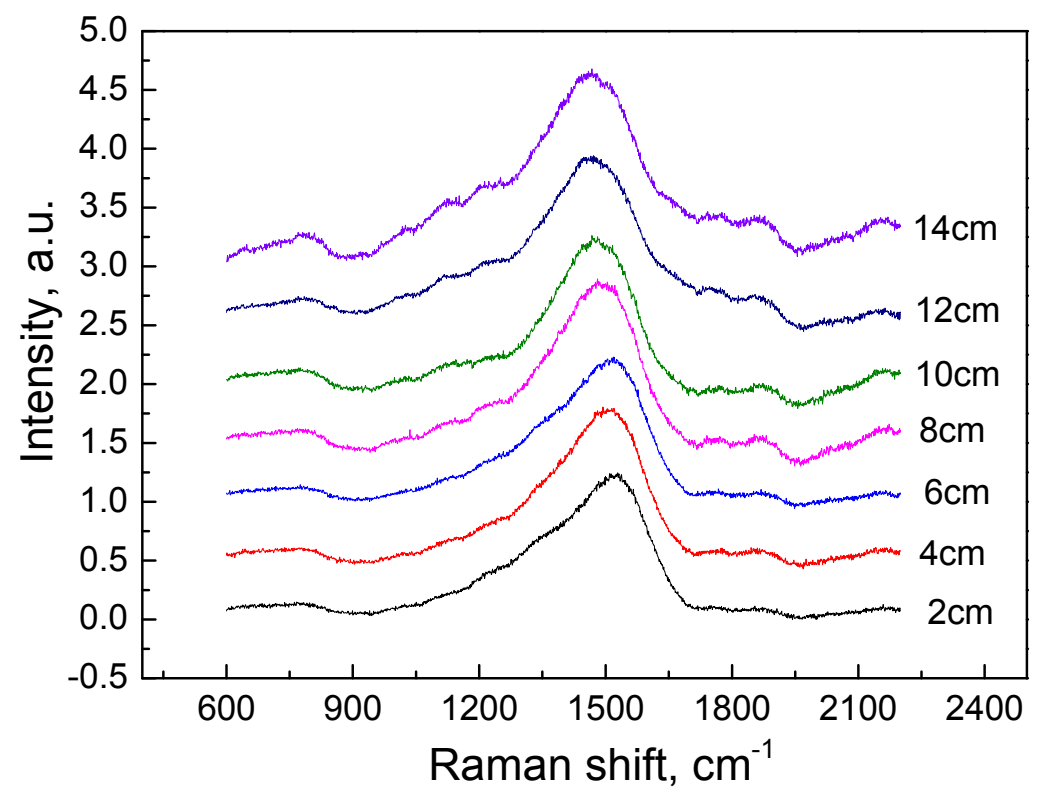

Fig. 13 